\title{
VALORACIÓN DE EDITORIALES ESPECIALIZADAS EN COMUNICACIÓN, BIBLIOTECONOMÍA Y DOCUMENTACIÓN: ENCUESTA A PROFESORES E INVESTIGADORES
}

\author{
Elea Giménez-Toledo y Carlos Tejada-Artigas
}

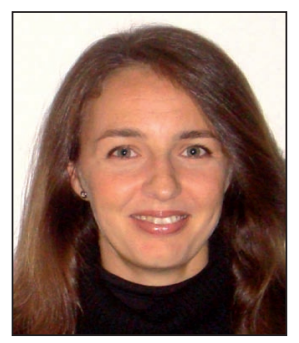

Elea Giménez-Toledo, científica titular del CSIC, es licenciada y doctora en documentación, y responsable del Grupo de Investigación de Evaluación de Publicaciones Científicas (EPUC) del Centro de Ciencias Humanas y Sociales. Su actividad investigadora se centra en los procesos de evaluación de la actividad científica en ciencias humanas y sociales. Diseña y aplica indicadores de calidad para revistas científicas y editoriales de libros. Es coautora de las plataformas de evaluación de revistas DICE, RESH y CIRC y es responsable de la parte española de Latindex.

G. I. Evaluación de Publicaciones Científicas (EPUC) Instituto de Estudios Documentales sobre Ciencia y Tecnología (ledcyt) Centro de Ciencias Humanas y Sociales (CCHS) Consejo Superior de Investigaciones Científicas (CSIC) Albasanz, 26-28. 28037 Madrid elea.gimenez@cchs.csic.es

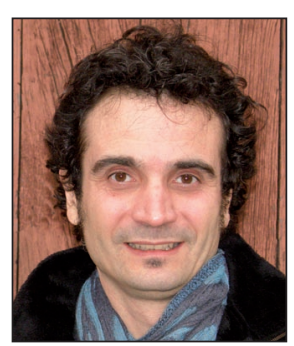

Carlos Tejada-Artigas es doctor en documentación por la Universidad Carlos III de Madrid y licenciado en geografía e historia por la Universidad Complutense de Madrid (UCM). Profesor titular de la Facultad de Ciencias de la Documentación de esta última universidad. Miembro de la junta directiva de Sedic, coordinador editorial de la revista El profesional de la información y coordinador del Grupo de Trabajo de Perfiles Profesionales del Consejo de Cooperación Bibliotecaria del Ministerio de Cultura. Sus principales líneas de investigación son el mercado de trabajo en información y documentación, competencias profesionales y publicaciones científicas.

Facultad de Ciencias de la Documentación Universidad Complutense de Madrid Santísima Trinidad 37. 28010 Madrid cmtejada@pdi.ucm.es

\section{Resumen}

Se analizan los procesos de publicación de libros científicos y las editoriales en Biblioteconomía y Documentación y en Comunicación. El método empleado ha sido un cuestionario dirigido a 263 investigadores y profesores españoles de estas áreas, del que se obtuvo una tasa de respuesta del 35,5\%. Los resultados permiten estudiar los indicadores de calidad de las editoriales que pueden tener una incidencia directa en la calidad de los libros que se editan, y los hábitos, opiniones y actitudes de los investigadores ante el proceso de selección y publicación de sus libros. Como resultado más pragmático se han identificado las editoriales españolas y extranjeras más prestigiosas para los investigadores de estas áreas.

\section{Palabras clave}

Editoriales, Libros, Indicadores de calidad, Evaluación de la investigación, Biblioteconomía y documentación, Comunicación.

\section{Title: Assessment of book publishers in Communication and LIS: survey to researchers and professors}

\begin{abstract}
Publishers of scholarly books about library and information science and communications are analyzed, as well as their publishing processes. The research method was a questionnaire sent to 263 Spanish researchers and teachers in these areas. The survey response rate was $35.5 \%$. Thanks to these responses, main quality indicators for publishers were identified. Researchers' working habits, opinions and attitudes related to the selection, editing and publishing processes of their books are also examined. Finally, as a more pragmatic result, the most prestigious Spanish and foreign publishers are identified.
\end{abstract}

\section{Keywords}

Publishers, Books, Quality indicators, Research evaluation, Library and information science, LIS, Communication. 
Giménez-Toledo, Elea; Tejada-Artigas, Carlos. "Valoración de editoriales especializadas en Comunicación, Biblioteconomía y Documentación: encuesta a profesores e investigadores". El profesional de la información, 2012, enerofebrero, v. 21, n. 1, pp. 50-62.

\section{Introducción}

La intensa actividad actual de evaluación de la investigación con el fin de asignar recursos, sexenios, acreditaciones, etc., ha traído consigo la necesidad de especificar cada vez con más claridad y precisión los indicadores de calidad, especialmente los de publicaciones.

Existen diversas fuentes internacionales y nacionales que aportan indicadores de calidad de distinta naturaleza sobre revistas (desde WoS, Scopus, ERIH y CIRC hasta DICE, RESH, In-Recs, MIAR, etc.), pero para los libros la situación es diferente. Los estudios de calidad de monografías tienen aún poca trayectoria, a pesar de que han sido demandados directa o indirectamente por humanistas y científicos sociales, la comunidad científica que más las valora y utiliza como vehículo de comunicación científica. Algunos precedentes en la evaluación de libros y editoriales (Cullars; 1992; 1998; Moed; Luwel; Nederhof, 2001; Hemlin; Gustafsson, 1996; Glänzel; Schoepflin, 1999) son revisados con detalle en el trabajo de Giménez-Toledo y Román-Román (2009) y pueden resumirse en:

- valoraciones de la calidad de las editoriales por parte de expertos;

- propuestas metodológicas para evaluar monografías;

- proyectos experimentales de evaluación cualitativa de libros $^{1}$.

Exceptuando Google Scholar y el recién estrenado Book Citation Index (Thomson Reuters), que ofrecen datos de citas a libros, no existen fuentes que proporcionen indicadores de calidad directos o indirectos. Sin embargo parece necesario que existan, a la luz de la precisión que han de tener los actuales sistemas de evaluación y para contribuir a que sean lo más objetivos posible.

En esta línea de trabajo se inscribe este artículo que pretende dar voz a la comunidad científica española de humanistas y científicos sociales en asuntos relacionados con la evaluación de monografías. El trabajo se ha llevado a cabo en el marco de un proyecto más amplio ${ }^{2}$ que ha tenido como objetivo estudiar los indicadores que pueden tener una incidencia directa en la calidad de los libros que se editan, en los hábitos, opiniones y actitudes de los investigadores ante el proceso de selección y publicación de sus libros y, como objetivo más pragmático, identificar las editoriales españolas y extranjeras más prestigiosas para los investigadores. Este proyecto ha sido desarrollado para todas las disciplinas de las humanidades y las ciencias sociales y lo que se presenta en este trabajo es un análisis sectorial en las áreas de Comunicación y Documentación, ya que son las de interés específico para los lectores de esta revista.

El estudio de las editoriales propiamente dichas es objeto de un artículo complementario a éste, publicado en otra revista, que pretende constituirse en una herramienta de con- sulta para esclarecer cuáles son las editoriales prestigiosas según la comunidad científica.

\section{Objetivos}

Con el objetivo general de conocer mejor los indicadores de calidad para libros científicos y objetivar en cierto modo el indicador "prestigio de la editorial" -referido por las agencias de evaluación pero poco concretado-, este trabajo se plantea los siguientes objetivos específicos:

- validar con los investigadores unos indicadores que puedan determinar la calidad de las editoriales con publicaciones científicas en ciencias sociales y humanidades;

- conocer las editoriales españolas y extranjeras que tienen más prestigio entre los investigadores;

- identificar los métodos más comunes de selección de originales seguidos por las editoriales a partir de la propia experiencia de los investigadores. Sin la pretensión de describir o analizar los casos particulares, el objetivo es conocer el comportamiento más habitual de las editoriales de carácter científico;

- saber si las editoriales científicas son transparentes en los procesos de selección de manuscritos;

- conocer en qué tipo de editoriales científicas publican los investigadores;

- determinar el proceso de toma de contacto entre investigadores y editoriales para la publicación de un texto;

- identificar los criterios de los investigadores a la hora de seleccionar una editorial para publicar;

- conocer si los investigadores pagan a las editoriales para publicar y/o si estarían dispuestos a ello.

Los estudios de calidad de los libros tienen aún poca trayectoria, a pesar de que han sido demandados por los humanistas y científicos sociales

\section{Metodología}

El método empleado ha sido la encuesta. El cuestionario utilizado contó con un total de catorce preguntas, divididas en tres apartados:

- perfil del investigador;

- valoración de la calidad de una editorial con publicaciones científicas;

- valoración del proceso de edición de una editorial con publicaciones científicas.

Antes de difundirla entre los destinatarios, fue probada por varios investigadores y expertos en la materia para tener la certeza de que las preguntas estaban claramente planteadas, así como para detectar faltas de funcionalidad en el diseño. 
El cuestionario se realizó en html y se alojó en un servidor del Centro de Ciencias Humanas y Sociales del CSIC.

Al enviar el cuestionario, los datos alimentaron mediante php una base de datos MySQL y una vez concluido el período de respuesta se exportaron al programa estadístico SPSS 17.

La encuesta se difundió entre investigadores y profesores, solicitando su cooperación por correo electrónico. Se les animó a participar mediante dos mensajes, el 15 de junio y el 15 de julio de 2010. La encuesta estuvo abierta a la participación durante el período del 15 de junio al 22 de agosto de 2010 . Con un universo de 11.647 profesores e investigadores españoles de universidad y del CSIC que cuentan al menos con un sexenio de investigación, se obtuvieron 3.045 respuestas, lo que supone una tasa de respuesta del $27 \%$.

Para las disciplinas de Biblioteconomía y Documentación y de Comunicación (que engloba las áreas de Periodismo, Comunicación audiovisual y Publicidad), la encuesta fue enviada a 263 académicos y respondieron 94, lo que supone una tasa de respuesta del $35,5 \%$, un porcentaje elevado para este tipo de estudios.

En el caso de Biblioteconomía y Documentación, la encuesta fue enviada a 92 académicos y respondieron 41, el 44,57\%. Hay que destacar que fue el tercer colectivo que más participó, tras Filología eslava y Didáctica de la expresión corporal, que alcanzaron las tasas de respuesta más altas. Por su parte, de Comunicación contestaron 53 de 171, el 31\% (27 de Comunicación Audiovisual y Publicidad de 86, y 26 de Periodismo de 85).

A continuación se analizan los resultados obtenidos por los diferentes apartados, según los objetivos propuestos.

\section{Resultados}

\subsection{Perfil del investigador}

\section{Organismo en el que trabaja}

El $97 \%$ de las 91 personas que contestaron a esta pregunta provienen de la universidad, mientras que el $2,2 \%$ proceden del CSIC. Las instituciones que más participaron fueron la Universidad Complutense de Madrid (18 académicos), Autònoma de Barcelona (12) y Carlos III de Madrid (10). En la tabla 1 se presentan todas las respuestas obtenidas.

\subsection{Valoración de la calidad de una editorial con pu- blicaciones científicas}

\section{Características que avalan la calidad de una editorial}

En el cuestionario se presentaba una serie de indicadores agrupados para que los investigadores señalaran cuáles les parecían importantes para medir la calidad de una editorial. Analizar esta información puede servir para conocer el grado de aceptación que tienen en la comunidad científica los indicadores que actualmente emplean las agencias de evaluación.

Como muestra la tabla 2, los seis indicadores más importantes a juicio de los investigadores son:

- trayectoria continuada de la editorial, indicado por 80 investigadores (el 85,1\% de los que respondieron);
- sistema de evaluación mediante revisores externos (77 investigadores, el 81,9\%);

- presencia en bibliotecas especializadas nacionales y extranjeras (73, el 77,7\%);

- presencia en bases de datos internacionales de las monografías publicadas por la editorial (70, el 74,5\%);

- editorial con colecciones especializadas (67, el 71,3\%);

- presencia en librerías especializadas nacionales y extranjeras $(67$, el $71,3 \%)$.

Entre los indicadores más importantes de calidad editorial están la trayectoria continuada y el sistema de evaluación mediante revisores externos

En algunos indicadores hubo diferencia entre las tasas de respuesta de los académicos de Comunicación y de Biblioteconomía y Documentación. Por ejemplo estos últimos señalaron más porcentualmente los siguientes indicadores:

- especialización de la editorial (70,7\% Biblioteconomía frente a $37,7 \%$ Comunicación);

- coordinación de la obra (46,3\% frente a 24,5\%);

\begin{tabular}{|c|c|c|c|}
\hline Organismo & $\begin{array}{l}\text { Acróni- } \\
\text { mo }\end{array}$ & $\begin{array}{c}\text { Fre- } \\
\text { cuen- } \\
\text { cia }\end{array}$ & $\begin{array}{l}\text { Por- } \\
\text { centaje }\end{array}$ \\
\hline Universitat Autònoma de Barcelona & $U A B$ & 12 & 13,2 \\
\hline Universidad de Alcalá de Henares & $U A H$ & 2 & 2,2 \\
\hline Universitat de Barcelona & $U B$ & 3 & 3,3 \\
\hline Universidad Carlos III de Madrid & UC3M & 10 & 11,0 \\
\hline Universidad Cardenal Herrera CEU & $\begin{array}{l}\text { UCH- } \\
\text { CEU }\end{array}$ & 1 & 1,1 \\
\hline Universidad Complutense de Madrid & UCM & 18 & 19,8 \\
\hline Universidad de Granada & UGR & 3 & 3,3 \\
\hline Universidad Jaime I & 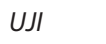 & 1 & 1,1 \\
\hline Universidad de La Laguna & $U L L$ & 2 & 2,2 \\
\hline Universidad de Murcia & UM & 5 & 5,5 \\
\hline Universidad de Málaga & UMA & 3 & 3,3 \\
\hline Universidad de Extremadura & UNEX & 3 & 3,3 \\
\hline Universidad de León & $\begin{array}{l}\text { UNI- } \\
\text { LEON }\end{array}$ & 1 & 1,1 \\
\hline Universidad de Zaragoza & UNIZAR & 3 & 3,3 \\
\hline Universitat Pompeu Fabra & UPF & 3 & 3,3 \\
\hline Universidad del País Vasco & $\begin{array}{l}\text { UPVI } \\
\text { EHU }\end{array}$ & 4 & 4,4 \\
\hline Universidad Rey Juan Carlos & URJC & 2 & 2,2 \\
\hline Universitat Rovira i Virgili & URV & 3 & 3,3 \\
\hline Universidad de Sevilla & US & 4 & 4,4 \\
\hline Universidad de Salamanca & USAL & 2 & 2,2 \\
\hline Universidad de Valencia & UV & 3 & 3,3 \\
\hline Universidad de Valladolid & UVA & 1 & 1,1 \\
\hline $\begin{array}{l}\text { Consejo Superior de Investigaciones } \\
\text { Científicas }\end{array}$ & CSIC & 2 & 2,2 \\
\hline \multicolumn{2}{|l|}{ Total } & 91 & 100,0 \\
\hline
\end{tabular}

Tabla 1. Número de respuestas por organismos 
- evaluación positiva de la editorial por parte de las agencias $(61 \%$ frente a $39,6 \%)$;

- marketing editorial (24,4\% frente a $11,3 \%)$;

- estructura adecuada (75,6\% frente a $47,2 \%)$.

En cambio y sorprendentemente, la presencia de la editorial en bibliotecas especializadas nacionales y extranjeras fue señalada más por los investigadores de Comunicación que por los de Biblioteconomía (84,9\% frente a 68,3\%).

Conscientes de que la relación de indicadores propuesta podía resultar incompleta, se reservó un espacio para que los encuestados pudieran sugerir otros o matizar el significado de algunos.

Uno de los indicadores que se añaden, y que es mencionado por varios investigadores, es el número de citas que recibe cada obra. No se incorporó en el momento de enviar la encuesta por la falta de fuentes que podían aportar estos valores. No obstante, Google Scholar calcula las citas recibidas por libros y Book Citation Index también lo hace, aunque con un universo más limitado. Las reticencias de los humanistas y de algunos científicos sociales hacia los indicadores de impacto también influyeron a la hora de excluir el indicador de la relación.

Al mismo tiempo que se mencionan las citas recibidas por las monografías como indicador de calidad, algunos comentarios se refieren a la cantidad de personas que leen y usan la obra. Al margen de las citas, es difícil conocer estos datos de "consumo" de las obras. La tirada, las ventas de la obra y el número de ediciones y traducciones, las consultas y préstamos en bibliotecas, así como las citas serían los datos más cercanos y más precisos sobre consumo.

Otro parámetro es la diversidad en el tipo de obras que publica una editorial; es decir, que acoja tanto obras individuales como colectivas, de creación original o procedentes de congresos y textos de distinta naturaleza.

También se alude a la profesionalización de la edición, esto es, al hecho de que la editorial cuente con responsables es-

\begin{tabular}{|c|c|c|c|c|c|c|}
\hline \multirow[b]{2}{*}{ Indicador } & \multicolumn{2}{|c|}{ Total } & \multicolumn{2}{|c|}{ Comunicación } & \multicolumn{2}{|c|}{$\begin{array}{c}\text { Biblioteconomía y } \\
\text { documentación }\end{array}$} \\
\hline & Frecuencia & $\%$ & Frecuencia & $\%$ & Frecuencia & $\%$ \\
\hline \multicolumn{7}{|l|}{ Sistema de evaluación de originales mediante revisores } \\
\hline Comités de lectura especializados & 54 & 57,4 & 31 & 58,5 & 23 & 56,1 \\
\hline Revisores externos & 77 & 81,9 & 42 & 79,2 & 35 & 85,4 \\
\hline Información sobre el proceso de selección de originales & 52 & 55,3 & 29 & 54,7 & 23 & 56,1 \\
\hline \multicolumn{7}{|l|}{ Especialización temática } \\
\hline Editorial especializada & 49 & 52,1 & 20 & 37,7 & 29 & 70,7 \\
\hline Editorial con colecciones especializadas & 67 & 71,3 & 39 & 73,6 & 28 & 68,3 \\
\hline Cantidad de publicaciones sobre la materia & 19 & 20,2 & 11 & 20,8 & 8 & 19,5 \\
\hline \multicolumn{7}{|l|}{ Prestigio } \\
\hline Trayectoria continuada de la editorial & 80 & 85,1 & 45 & 84,9 & 35 & 85,4 \\
\hline Reseñas positivas en las mejores revistas del área & 55 & 58,5 & 28 & 52,8 & 27 & 65,9 \\
\hline Número de títulos y tirada de cada uno de ellos & 18 & 19,1 & 12 & 22,6 & 6 & 14,6 \\
\hline Editor de relevancia en la colección o en la editorial & 55 & 58,5 & 26 & 49,1 & 29 & 70,7 \\
\hline Coordinador de la obra & 32 & 34,0 & 13 & 24,5 & 19 & 46,3 \\
\hline $\begin{array}{l}\text { Que las agencias de evaluación (Aneca, Cneai, etc.) valoren positivamente } \\
\text { a esa editorial }\end{array}$ & 46 & 48,9 & 21 & 39,6 & 25 & 61,0 \\
\hline \multicolumn{7}{|l|}{ Sistema de difusión y distribución } \\
\hline Presencia en librerías especializadas nacionales y extranjeras & 67 & 71,3 & 41 & 77,4 & 26 & 63,4 \\
\hline Presencia en bibliotecas especializadas nacionales y extranjeras & 73 & 77,7 & 45 & 84,9 & 28 & 68,3 \\
\hline $\begin{array}{l}\text { Presencia en bases de datos internacionales de las monografías } \\
\text { publicadas por la editorial }\end{array}$ & 70 & 74,5 & 38 & 71,7 & 32 & 78,0 \\
\hline $\begin{array}{l}\text { Traducciones en distintos idiomas de las monografías publicadas por la } \\
\text { editorial }\end{array}$ & 40 & 42,6 & 21 & 39,6 & 19 & 46,3 \\
\hline Marketing editorial & 16 & 17,0 & 6 & 11,3 & 10 & 24,4 \\
\hline Proyección internacional de la editorial & 54 & 57,4 & 29 & 54,7 & 25 & 61,0 \\
\hline Que la editorial coedite & 10 & 10,6 & 5 & 9,4 & 5 & 12,2 \\
\hline \multicolumn{7}{|l|}{ Calidad de las ediciones } \\
\hline Presentación formal & 51 & 54,3 & 29 & 54,7 & 22 & 53,7 \\
\hline Estructura adecuada & 56 & 59,6 & 25 & 47,2 & 31 & 75,6 \\
\hline Índices de autores, temas, onomásticos, etc. & 54 & 57,4 & 30 & 56,6 & 24 & 58,5 \\
\hline $\begin{array}{l}\text { Formato de las monografías (que también se ofrezcan como libro } \\
\text { electrónico o ebook) }\end{array}$ & 41 & 43,6 & 20 & 37,7 & 21 & 51,2 \\
\hline
\end{tabular}

Tabla 2. Indicadores de calidad de las editoriales 
pecializados en la dirección editorial y en los procesos técnicos, a que haya un control editorial serio y riguroso, no guiado por intereses comerciales, y a que exista un esquema de trabajo bien definido y asumido en cada una de sus fases por especialistas.

La correcta identificación de todos los datos que constituyen la referencia bibliográfica, que son indispensables para catálogos de bibliotecas y bases de datos bibliográficas, es señalada como otra característica importante. Sin duda, se trata de un aspecto que valoran los especialistas de estas áreas (Ciencias de la información) y que probablemente no haya sido destacado en otras disciplinas.

Algún investigador también mencionó la calidad de la obra establecida por los propios expertos del área, es decir, una evaluación cualitativa similar a la llevada a cabo por la agencia catalana de evaluación, en colaboración con la UAB, a modo de proyecto piloto (AQU Catalunya, 2010).

Otros aspectos señalados son:

- la selección de títulos por su interés científico y no tanto por sus posibilidades de éxito comercial;

- la permanencia de la obra a lo largo de los años para que no desaparezcan del mercado títulos interesantes;

- que las editoriales acojan obras de autores jóvenes y no sólo de los consagrados;

- que la evaluación no sea anónima;

- que publique manuales de referencia relevantes;

- que sus obras sean útiles tanto para la investigación como para la docencia;

- que editen a los científicos e intelectuales más reconocidos internacionalmente;

- que la editorial tenga proyección internacional; y

- que no esté influenciada por los valores o prioridades del grupo de comunicación o académico al que pertenezca, es decir, que sea imparcial y plural. Este "indicador" es sin duda deseable, pero algo utópico y, sobre todo, difícil de valorar de manera objetiva.

El prestigio de una editorial es una cualidad a la que se refieren las agencias de evaluación a pesar de ser un concepto subjetivo

Valoración de las características generales que avalan la calidad de una editorial

Se pedía asimismo que puntuaran de 0 al 5 los indicadores de calidad de una editorial tratados en la pregunta anterior. Las medias obtenidas por los distintos indicadores son parecidas (gráfico 1 ) y no presentan desviaciones típicas significativas ${ }^{3}$, siendo el sistema de evaluación de originales mediante revisores el que logra una mayor valoración (4). En el otro extremo está el formato de libro electrónico que es la característica que menos puntuación ha tenido $(2,62)$. Las otras valoraciones por orden de importancia han sido: especialización temática de la editorial (3,95\%); prestigio $(3,93)$; sistema de difusión y distribución $(3,64)$; y calidad de las ediciones $(3,52)$.

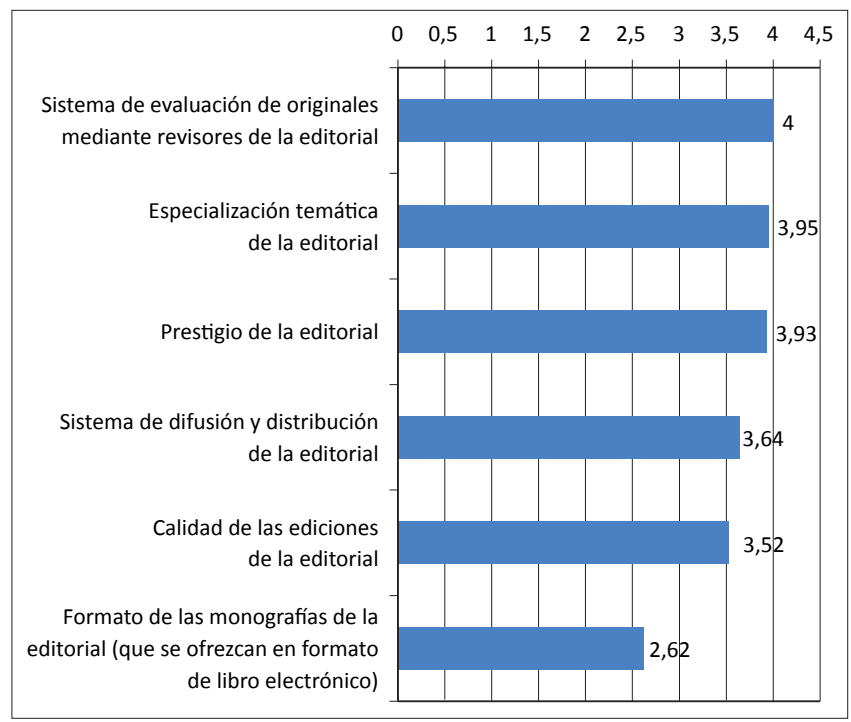

Gráfico 1. Valoración de las características de calidad de una editorial (medias)

\section{Razones de elección de una editorial para publicar}

Se incluía una pregunta en la que se pedía a los investigadores que señalaran las razones que les habían llevado a elegir una determinada editorial para publicar. La pregunta era multirespuesta, ya que podían elegir varias opciones de una lista cerrada. El procesamiento de los datos obtenidos señala las siguientes razones por orden de importancia:

- prestigio de la editorial (69\% de los que contestaron);

- especialización temática de la editorial o de la colección (65\%);

- buen sistema de difusión y distribución en librerías y bibliotecas $(46,8 \%)$;

- presencia en bases de datos internacionales de los libros publicados (31\%);

- buena calidad de la edición (29,8\%);

- facilidad en la aceptación del texto ya que se trata de una editorial de la institución en la que trabaja el investigador $(12,8 \%)$;

- facilidad en la aceptación del texto por tratarse de una editorial en expansión (3,2\%).

Si se comparan los resultados de las dos áreas, se observa que en Comunicación se valora más que en Documentación el prestigio de la editorial ( $77 \%$ frente al $59 \%$ ) y el buen sistema de difusión y distribución en librerías y bibliotecas de los libros publicados (62\% frente a $27 \%$ ), tal como ya se observaba en la pregunta anterior. En el gráfico 2 se muestra la representación de todos los porcentajes obtenidos.

\section{Editoriales españolas más prestigiosas}

La evaluación de las editoriales es una posible aproximación a la calidad de los títulos que publica cada una. Aunque éstas pueden exigir comportamientos distintos a cada colección -algunas más científicas y rigurosas, otras más divulgativas y/o comerciales, etc.- lo cierto es que un sello editorial suele estar asociado a un nivel de calidad determinado. Sin duda alguna, el análisis cualitativo de cada obra publicada es el que mejor puede juzgar el trabajo de un investigador. Sin embargo, el volumen de obras publicadas, así como los variados procesos de evaluación que existen hacen impo- 


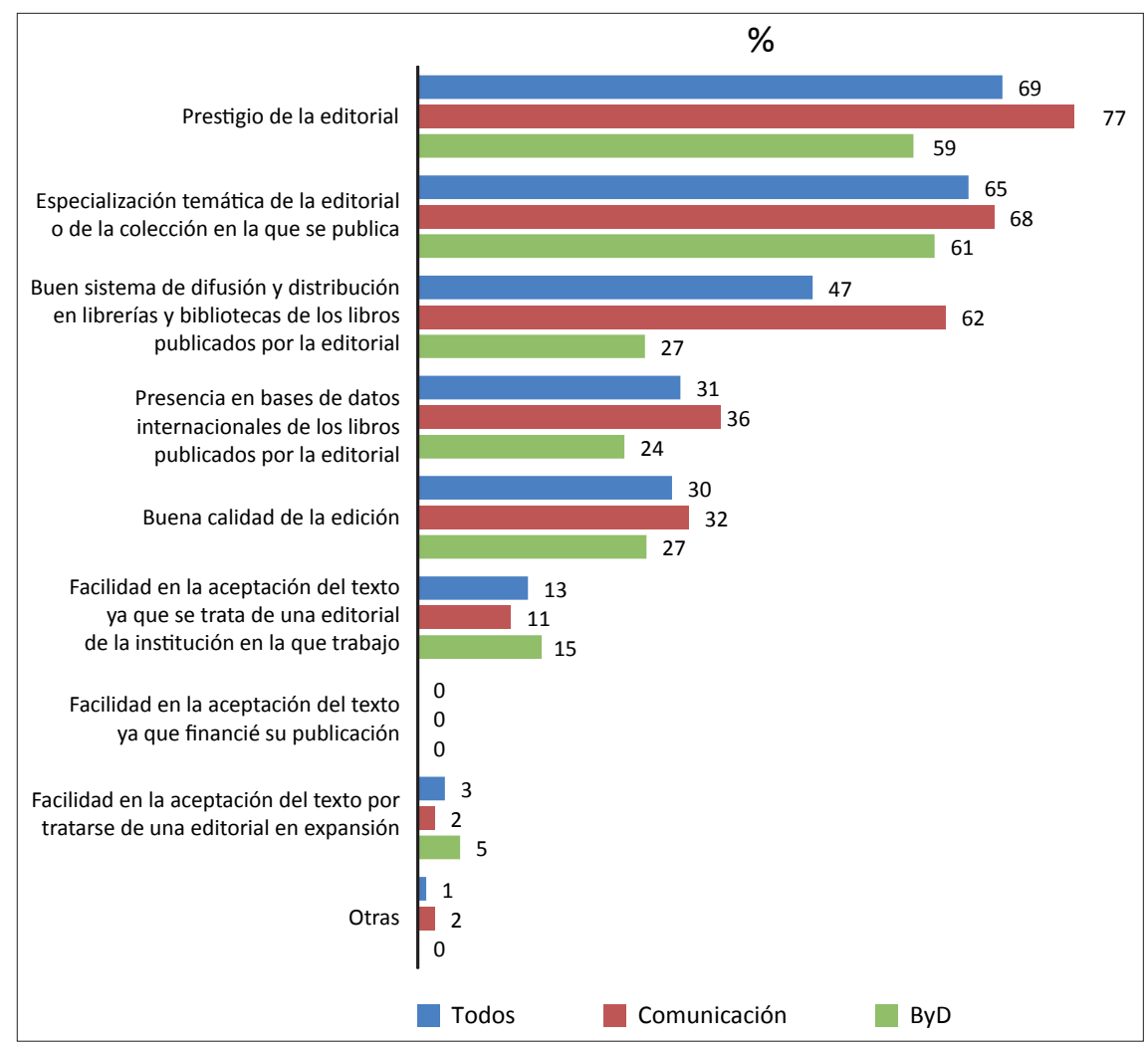

Gráfico 2. Razones de elección de la editorial

sible abordar un análisis de esas características. Por eso, la evaluación de las editoriales representa un ejercicio viable, que permitirá a los gestores de política científica contar con una herramienta orientativa en sus procesos de evaluación.

Conocer las editoriales "prestigiosas" ayuda en los procesos de evaluación

El prestigio de una editorial es factor al que se refieren habitualmente las agencias de evaluación de la actividad científica como indicador de calidad de los libros publicados (Cneai, 2009; Aneca, ANEP, etc.). Sin embargo, el prestigio es en sí mismo un concepto ciertamente subjetivo. Un investigador puede considerar que una editorial es prestigiosa porque haya leído buenos libros publicados por ella, porque le ha publicado los suyos, porque sus ediciones son cuidadas y atractivas, porque sus obras hayan pasado por una evaluación rigurosa en esa editorial o porque la mayor parte de la comunidad científica opine que esa editorial es prestigiosa.

Conocer qué editoriales son descritas como "prestigiosas" por los expertos de un área puede resultar una vía interesante para contar con listados de editoriales de referencia que ayuden o guíen en los procesos de evaluación. Resulta necesario disponer de alguna herramienta en ese sentido, desde el momento en que apenas hay indicadores de calidad directos para evaluar la producción científica a través de los libros y sabiendo que es un elemento clave en los procesos de evaluación.

Así pues, en la encuesta se pedía a los participantes que señalaran, por orden de importancia, las tres editoriales españolas y las tres extranjeras que, a su juicio, tienen más Documentación prestigio en su área. Al ser una pregunta abierta se tuvieron que normalizar todas las editoriales mencionadas.

Los editoriales señaladas y los votos que recibieron se muestran en las tablas 3 y 4 .

Editoriales extranjeras más prestigiosas

En el caso de las editoriales extranjeras, el planteamiento de la pregunta fue similar a la anterior. Estos resultados indican una mayor dispersión que en el caso de las editoriales españolas, ya que los investigadores han señalado 32 editoriales extranjeras distintas (frente a las 17 españolas) en Biblioteconomía y Documentación, y 43 en Comunicación (frente a las 29 españolas) (tablas 5 y 6).

\subsection{Valoración del proceso de edi- ción de una editorial con publica- ciones científicas}

Investigadores que han publicado una monografía científica en una editorial

Como resulta obvio, interesaba que opinaran y valoraran el proceso de edición en las editoriales aquellos investigadores que tuvieran libros publicados y, por tanto, hubieran pasado por un proceso de selección y de edición. Por esta razón, la primera pregunta que se les hacía era si alguna vez habían publicado libros. Como era de esperar, una mayoría

\begin{tabular}{|c|c|c|c|c|}
\hline Editorial & $\begin{array}{l}N^{\circ} \text { total } \\
\text { de votos }\end{array}$ & $\begin{array}{l}\text { No votos } \\
\text { en } 1^{\text {a }} \\
\text { posición }\end{array}$ & $\begin{array}{l}N^{\circ} \text { votos } \\
\text { en } 2^{\mathrm{a}} \\
\text { posición }\end{array}$ & $\begin{array}{l}N^{\circ} \text { votos } \\
\text { en } 3^{\mathrm{a}} \\
\text { posición }\end{array}$ \\
\hline Trea & 27 & 18 & 7 & 2 \\
\hline Sintesis & 19 & 4 & 11 & 4 \\
\hline $\begin{array}{l}\text { Fundación Germán } \\
\text { Sánchez Ruipérez }\end{array}$ & 6 & 2 & 2 & 2 \\
\hline Pirámide & 5 & 1 & 1 & 3 \\
\hline $\mathrm{Ra}-\mathrm{Ma}$ & 2 & 1 & 1 & \\
\hline Cátedra & 2 & 1 & 1 & \\
\hline Arco Libros & 3 & & 1 & 2 \\
\hline CSIC & 2 & 1 & & 1 \\
\hline Ollero y Ramos & 1 & 1 & & \\
\hline Anaya & 1 & 1 & & \\
\hline Santillana & 1 & 1 & & \\
\hline Díaz de Santos & 2 & & 1 & 1 \\
\hline Alianza & 2 & & 1 & 1 \\
\hline Troa & 1 & & 1 & \\
\hline Eunsa & 1 & & & 1 \\
\hline Paidós & 1 & & & 1 \\
\hline Pearson Educación & 1 & & & 1 \\
\hline Total & 77 & 31 & 27 & 19 \\
\hline
\end{tabular}

Tabla 3. Editoriales españolas con más prestigio en Biblioteconomía y 
de los académicos $(93,4 \%)$ respondió afirmativamente a la pregunta.

Tipo de editorial en la que han publicado los investigadores

Los investigadores que contestaron afirmativamente fueron preguntados sobre el tipo de editorial en la que habían publicado sus libros. Puesto que usualmente los investigadores tienen más de un libro publicado, la pregunta es multirespuesta y los datos que se ofrecen son frecuencias de publicación en los distintos tipos de editoriales.

Predomina la publicación en:

- editoriales científicas universitarias españolas (55,3\% de los investigadores que han respondido a la encuesta);

- editorial científica comercial española (53,2\%);

- editorial comercial española con colecciones científicas $(41,5 \%)$;

\begin{tabular}{|c|c|c|c|c|}
\hline Editorial & $\begin{array}{l}\text { No total } \\
\text { de votos }\end{array}$ & $\begin{array}{c}N^{N} \text { votos } \\
\text { en } 1^{\text {a }} \\
\text { posición }\end{array}$ & $\begin{array}{c}N^{\circ} \text { votos } \\
\text { en } 2^{\mathrm{a}} \\
\text { posición }\end{array}$ & $\begin{array}{l}N^{\circ} \text { votos } \\
\text { en } 3^{\mathrm{a}} \\
\text { posición }\end{array}$ \\
\hline Paidós & 30 & 14 & 8 & 8 \\
\hline Cátedra & 22 & 15 & 1 & 6 \\
\hline Gedisa & 12 & 1 & 8 & 3 \\
\hline Ariel & 9 & 4 & 3 & 2 \\
\hline Sintesis & 9 & & 7 & 2 \\
\hline Tecnos & 8 & 2 & 2 & 4 \\
\hline Bosch & 4 & 3 & 1 & \\
\hline Alianza & 4 & 2 & 2 & \\
\hline Gustavo Gili & 3 & 1 & & 2 \\
\hline Biblioteca Nueva & 3 & & 2 & 1 \\
\hline Fragua & 3 & & 1 & 2 \\
\hline Eunsa & 2 & & 1 & 1 \\
\hline Rialp & 2 & & 1 & 1 \\
\hline Tirant lo Blanch & 2 & & 1 & 1 \\
\hline $\begin{array}{l}\text { Universidad del País } \\
\text { Vasco }\end{array}$ & 1 & 1 & & \\
\hline $\begin{array}{l}\text { Iberoamericanal } \\
\text { Vervuert }\end{array}$ & 1 & & 1 & \\
\hline Trotta & 1 & & 1 & \\
\hline $\begin{array}{l}\text { Universitat de } \\
\text { València }\end{array}$ & 1 & & 1 & \\
\hline $\begin{array}{l}\text { Caja España (Apren- } \\
\text { der a mirar) }\end{array}$ & 1 & & 1 & \\
\hline Delta & 1 & & 1 & \\
\hline Aldea Global & 1 & & 1 & \\
\hline Filmoteca Española & 1 & & & 1 \\
\hline Pearson Educación & 1 & & & 1 \\
\hline Pirámide & 1 & & & 1 \\
\hline Anthropos & 1 & & & 1 \\
\hline $\begin{array}{l}\text { Universitat Oberta } \\
\text { de Catalunya }\end{array}$ & 1 & & & 1 \\
\hline Castalia & 1 & & & 1 \\
\hline Crítica & 1 & & & 1 \\
\hline $\begin{array}{l}\text { Diputación de } \\
\text { Sevilla }\end{array}$ & 1 & & & 1 \\
\hline Total & 128 & 43 & 44 & 41 \\
\hline
\end{tabular}

Tabla 4. Editoriales españolas con más prestigio en Comunicación
- editorial científica de organismo de investigación español $(18,1 \%)$;

- editorial comercial extranjera con colecciones científicas (17\%);

- editorial científica universitaria extranjera (14,9\%);

- editorial científica comercial extranjera (14,9\%);

- autoedición del texto $(6,4 \%)$;

- editorial científica de organismo de investigación extranjero (3,2\%).

\begin{tabular}{|c|c|c|c|c|}
\hline Editorial & $\begin{array}{l}N^{\circ} \text { total } \\
\text { de votos }\end{array}$ & $\begin{array}{l}\text { No votos } \\
\text { en } 1^{\text {a }} \\
\text { posición }\end{array}$ & $\begin{array}{l}N^{\circ} \text { votos } \\
\text { en } 2^{\text {a }} \\
\text { posición }\end{array}$ & $\begin{array}{l}N^{\circ} \text { votos } \\
\text { en } 3^{a} \\
\text { posición }\end{array}$ \\
\hline Elsevier & 14 & 6 & 5 & 3 \\
\hline Springer & 10 & 7 & 1 & 2 \\
\hline McGraw Hill & 10 & 3 & 4 & 3 \\
\hline $\begin{array}{l}\text { American Library } \\
\text { Association }\end{array}$ & 9 & 3 & 4 & 2 \\
\hline De Gruyter & 6 & 2 & 1 & 3 \\
\hline Aslib & 2 & 1 & 1 & \\
\hline Libraries Unlimited & 3 & 1 & & 2 \\
\hline $\begin{array}{l}\text { Pearson Education. } \\
\text { Addison-Wesley }\end{array}$ & 3 & & 2 & 1 \\
\hline $\begin{array}{l}\text { Universidad Nacio- } \\
\text { nal Autónoma de } \\
\text { México. CUIB }\end{array}$ & 2 & & 2 & \\
\hline Facet & 2 & & 2 & \\
\hline IGI Global & 1 & 1 & & \\
\hline John Wiley and sons & 1 & 1 & & \\
\hline Asist & 1 & 1 & & \\
\hline $\begin{array}{l}\text { Oxford University } \\
\text { Press }\end{array}$ & 1 & 1 & & \\
\hline Reichenberger & 1 & 1 & & \\
\hline Vid. 5 & 1 & 1 & & \\
\hline$A C M$ & 1 & 1 & & \\
\hline Chandos Publishing & 1 & 1 & & \\
\hline Haworth Press & 1 & & 1 & \\
\hline $\begin{array}{l}\text { International Coun- } \\
\text { cil on Archives }\end{array}$ & 1 & & 1 & \\
\hline Pearson Education & 1 & & 1 & \\
\hline Blackwell & 1 & & 1 & \\
\hline $\begin{array}{l}\text { Scare Crow Prees, } \\
\text { Metuchen N. J. }\end{array}$ & 1 & & 1 & \\
\hline Taylor and Francis & 1 & & 1 & \\
\hline Academic Press & 1 & & 1 & \\
\hline $\begin{array}{l}\text { La Documentation } \\
\text { Francaise }\end{array}$ & 1 & & & 1 \\
\hline Auger & 1 & & & 1 \\
\hline Pergamon & 1 & & & 1 \\
\hline Sage & 1 & & & 1 \\
\hline Unesco & 1 & & & 1 \\
\hline Unlimited Books & 1 & & & 1 \\
\hline Alfagrama & 1 & & & 1 \\
\hline Total & 83 & 31 & 29 & 23 \\
\hline
\end{tabular}

Tabla 5. Editoriales extranjeras con más prestigio en Biblioteconomía y Documentación 


\begin{tabular}{|c|c|c|c|c|}
\hline Editorial & $\begin{array}{l}N^{\circ} \text { total } \\
\text { de votos }\end{array}$ & $\begin{array}{l}\text { No votos } \\
\text { en } 1^{\text {a }} \\
\text { posición }\end{array}$ & $\begin{array}{l}N^{\circ} \text { votos } \\
\text { en } 2^{\mathrm{a}} \\
\text { posición }\end{array}$ & $\begin{array}{c}N^{\circ} \text { votos } \\
\text { en } 3^{\mathrm{a}} \\
\text { posición }\end{array}$ \\
\hline Sage & 20 & 12 & 6 & 2 \\
\hline Routledge & 16 & 8 & 6 & 2 \\
\hline McGraw-Hill & 6 & 1 & 5 & \\
\hline Macmillan & 4 & 2 & 1 & 1 \\
\hline $\begin{array}{l}\text { Oxford University } \\
\text { Press }\end{array}$ & 6 & & 1 & 5 \\
\hline Blackwell & 3 & 1 & 2 & \\
\hline Taylor and Francis & 3 & 2 & & 1 \\
\hline $\begin{array}{l}\text { Cambridge Universi- } \\
\text { ty Press }\end{array}$ & 5 & & 2 & 3 \\
\hline Amorrortu & 3 & 1 & 1 & 1 \\
\hline Harmattan & 3 & 1 & & 2 \\
\hline $\begin{array}{l}\text { Harvard Unversity } \\
\text { Press }\end{array}$ & 2 & 1 & 1 & \\
\hline Intellect & 4 & & 1 & 3 \\
\hline Pearson Education & 3 & 1 & & 2 \\
\hline Hampton Press & 2 & & 2 & \\
\hline Focal Press & 2 & 1 & & 1 \\
\hline $\begin{array}{l}\text { Fondo de Cultura } \\
\text { Económica }\end{array}$ & 2 & 1 & & 1 \\
\hline Hachette & 1 & 1 & & \\
\hline $\begin{array}{l}\text { lowa University } \\
\text { Press }\end{array}$ & 2 & & 1 & 1 \\
\hline John Libbey Media & 1 & 1 & & \\
\hline Klincksieck & 1 & 1 & & \\
\hline $\begin{array}{l}\text { Manchester Univer- } \\
\text { sity Press }\end{array}$ & 2 & & 1 & 1 \\
\hline MIT Press & 1 & 1 & & \\
\hline Mondadori & 2 & & 1 & 1 \\
\hline Pearson & 1 & 1 & & \\
\hline Praeger & 1 & 1 & & \\
\hline $\begin{array}{l}\text { Princeton University } \\
\text { Press }\end{array}$ & 1 & 1 & & \\
\hline $\begin{array}{l}\text { California University } \\
\text { Press }\end{array}$ & 2 & & 1 & 1 \\
\hline $\begin{array}{l}\text { Facultade Social de } \\
\text { Bahia }\end{array}$ & 1 & 1 & & \\
\hline Ashgate & 1 & & 1 & \\
\hline Nomos & 1 & & 1 & \\
\hline Trillas & 2 & & & 2 \\
\hline $\begin{array}{l}\text { Columbia University } \\
\text { Press }\end{array}$ & 1 & & 1 & \\
\hline Gallimard & 1 & & 1 & \\
\hline $\begin{array}{l}\text { Éditions du } \\
\text { Nouveau Monde }\end{array}$ & 1 & & 1 & \\
\hline La Cruija & 1 & & & 1 \\
\hline La Découverte & 1 & & & 1 \\
\hline Polity & 1 & & & 1 \\
\hline $\begin{array}{l}\text { Presses Universitai- } \\
\text { res de France }\end{array}$ & 1 & & & 1 \\
\hline Unesco & 1 & & & 1 \\
\hline University of Illinois & 1 & & & 1 \\
\hline De Boeck & 1 & & & 1 \\
\hline Elsevier & 1 & & & 1 \\
\hline Free Press & 1 & & & 1 \\
\hline Total & 117 & 40 & 37 & 39 \\
\hline
\end{tabular}

Tabla 6. Editoriales extranjeras con más prestigio en Comunicación
Estos valores se refieren al conjunto de las dos áreas.

Al comparar los datos obtenidos entre investigadores de Biblioteconomía y Documentación y de Comunicación, se aprecia que estos últimos publican más en el extranjero. Sólo 4 investigadores en Biblioteconomía señalaron haber publicado en editoriales extranjeras, un dato indicativo del tipo de investigación más bien local que se realiza en el área o de la escasa proyección internacional que se le está dando a investigaciones que sí que podrían tener interés fuera. Así el $24,5 \%$ de los investigadores en Comunicación han publicado en editoriales científicas universitarias extranjeras frente a tan solo al 2,4\% de los de Biblioteconomía. Lo mismo ocurre con las publicaciones en editoriales científicas de organismos de investigación extranjeros (5,7\% frente al 0\%); la editorial científica comercial extranjera $(20,8 \%$ frente a $7,3 \%)$; y la editorial comercial extranjera con colecciones científicas (30,2\% frente al $0 \%)$.

Los investigadores de Comunicación publican más en el extranjero que los de Biblioteconomía y Documentación

Otra diferencia acusada entre las áreas se da en las editoriales de organismos de investigación españoles y extranjeros. En el primer caso, destaca Biblioteconomía y Documentación sobre Comunicación (con una ventaja de 14 puntos) por una clara razón: no hay apenas centros de investigación no vinculados a universidades en el área de la Comunicación, algo que sí ocurre con la Biblioteconomía pues, al menos dos institutos del CSIC se dedican a la Documentación científica.

El gráfico 3 muestra la diferencia de frecuencias para cada una de las dos disciplinas.

Proceso de toma de contacto con la editorial para la publicación del texto

En cuanto al proceso que siguieron los investigadores para que la editorial les publicara el texto, las opciones más señaladas por orden de importancia fueron:

a) los investigadores se pusieron en contacto con la editorial en un $55,3 \%$ de los casos;

b)la editorial se puso en contacto con los investigadores en un $48 \%$ de las ocasiones;

c) en un $51 \%$ fue el coordinador de una obra colectiva quien se puso en contacto con ellos para la redacción de un capítulo.

Otra forma, aunque ya de importancia menor, es la existencia de un concurso de carácter científico cuyo premio era la publicación del texto (2,1\%).

Los datos obtenidos muestran que en Biblioteconomía y Documentación es más frecuente que sean los editores quienes se pongan en contacto con los autores, mientras que en Comunicación es más habitual que sea el autor quien tome la iniciativa.

Los distintos porcentajes de respuesta pueden observarse en el gráfico 4. 


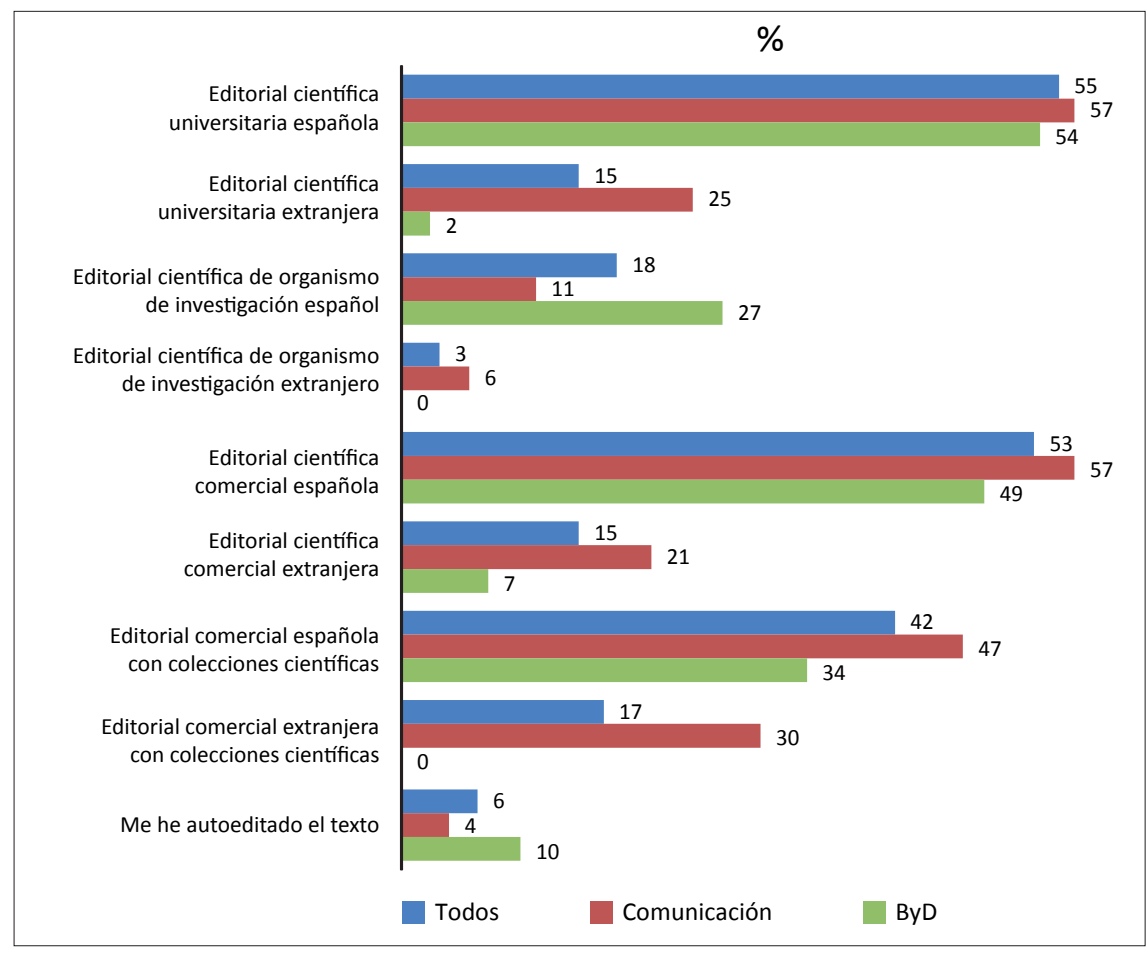

Gráfico 3. Tipo de editorial en la que han publicado

Claridad de la información que ofrecen las editoriales en relación con el envío de textos para su publicación

Uno de los aspectos que más diferencia a las editoriales de monografías frente a las revistas científicas es que no suele ser muy clara la información sobre la propuesta de textos para su publicación. Así se desprende de los resultados de esta encuesta, que incluía una pregunta sobre este asunto. Así, el 52\% de los investigadores que contestaron a esta pregunta señalaron que las editoriales sí que ofrecen una información clara para el envío de textos, pero también un $25 \%$ indicó que no y un $22 \%$ no tiene una opinión definida al respecto (gráfico 5).

Tanto en las respuestas positivas como en las negativas, parece que el colectivo de investigadores en Comunicación es más crítico en relación a la información proporcionada por las editoriales. El grupo de editoriales sobre el que pueden opinar es mayor y también lo es la masa crítica de investigadores. Por otra parte, esta comunidad científica se ha mantenido bastante crítica en relación a los asuntos de publicación y evaluación científica.

Los comentarios abiertos que los académicos realizaron en torno a esta pregunta resultaron especialmente expresivos. La opinión más extendida es que las editoriales son poco transparentes e incluso "opacas" en cuanto a la información que ofrecen para enviar un manuscrito. En algún caso se menciona:

- este comportamiento es propio de editoriales españolas, pero no de las estadounidenses;

- con la falta de información tratan de frenar el aluvión de originales que hay, debido a la presión por publicar;
- los autores deben ser insistentes en la petición de información a las editoriales hasta que la logran obtener;

- los autores desconocen, en términos generales, si su obra puede resultar interesante o no para una editorial, precisamente por esa falta de información.

Claridad de la información que ofrecen las editoriales en relación al proceso de aceptación de los textos.

Complementando la pregunta anterior se pedía a los académicos que señalaran si les parecía claro el proceso de aceptación de textos. Predominan las respuestas afirmativas (39\%), aunque contestaron negativamente un $32 \% \mathrm{y}$, por otra parte, un $29 \%$ no tienen una clara información al respecto. Estos dos últimos porcentajes son lo suficientemente altos como para que cobre un mayor interés el análisis de las preguntas abiertas. En términos generales, se observa que hay un cierto desconcierto con la información que ofrecen las editoriales y se reitera la idea de que el autor desconoce el proceso de evaluación que sigue una editorial. Por una parte, está claro que las editoriales no siguen un protocolo informativo hacia sus autores parecido al que se sigue en las revistas científicas, donde el autor suele estar informado en cada momento de la fase y la decisión que afecta a su original. Entre los comentarios, se repite la idea de que entre el envío del texto completo y la recepción de alguna información sobre su interés para la editorial, media una falta de comunicación entre autor y editor. Incluso se llega a afirmar que el autor ha de realizar una continuada labor de intento de contacto con la editorial para lograr información sobre el manuscrito.

Un aspecto que diferencia a las editoriales de monografías de las de revistas científicas es que no suele ser muy clara la información sobre la propuesta de textos para su publicación

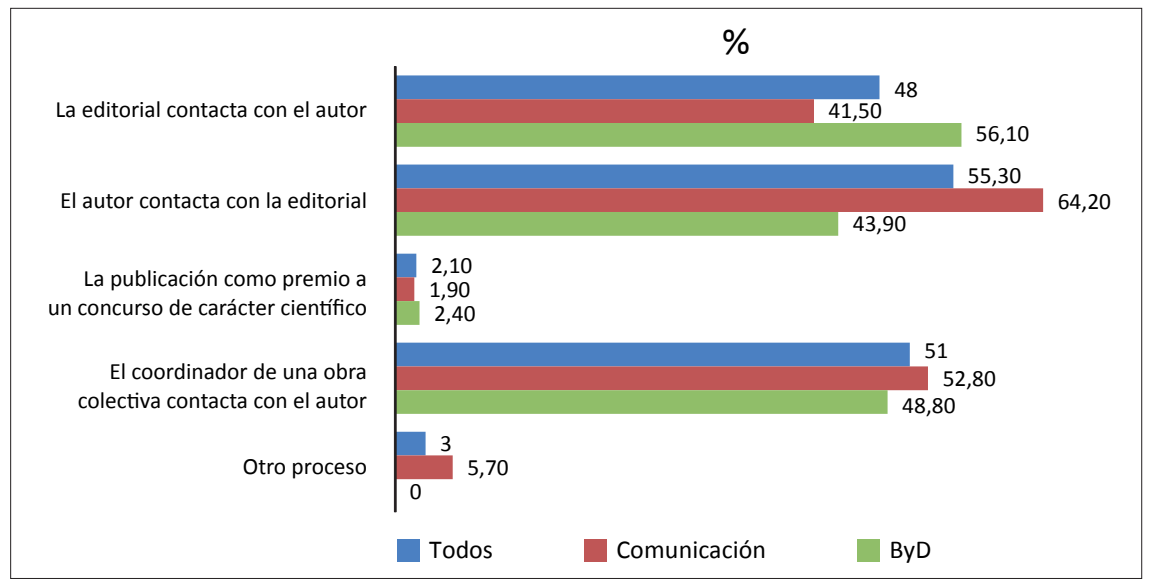

Gráfico 4. Forma de contacto entre la editorial y el autor 
Por otra parte, se mencionan algunas cuestiones realmente delicadas y también interesantes que convendría analizar, como por ejemplo, que las decisiones finales de publicación por parte de una editorial no sólo están relacionadas con la calidad de la obra sino también con su vinculación a asignaturas troncales que garanticen, de algún modo, la viabilidad económica de la edición. También se alude a que los grupos de presión impiden el acceso a la publicación a algunos autores, a la fase de "letargo" en que entran los originales a la espera de una evaluación e incluso a la creencia de que las editoriales publican todo lo que se les envía.

En cuanto a la comparativa por áreas, que se muestra en el gráfico 6, nuevamente se detecta una mayor actitud crítica de la comunidad especializada en Comunicación que puede tener que ver con el movimiento crítico que se ha dado en la

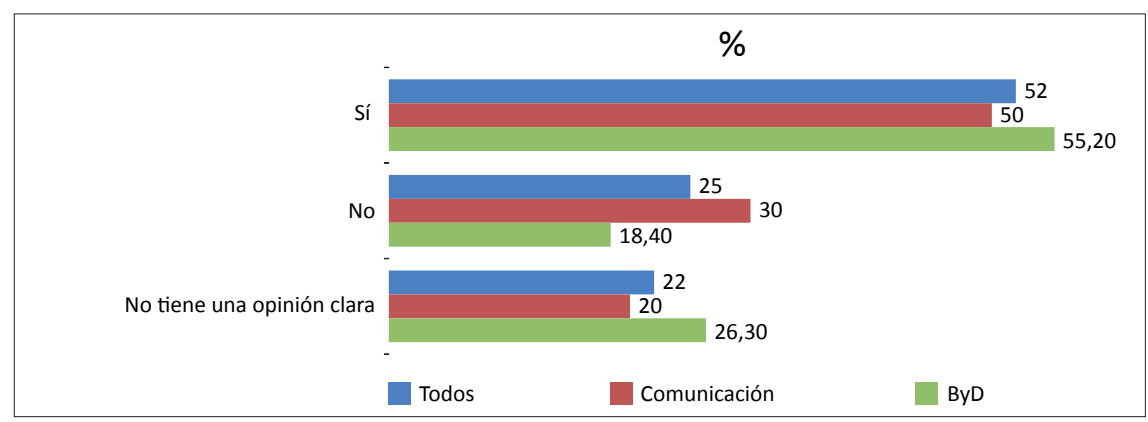

Gráfico 5. Opinión sobre la claridad de las editoriales en el proceso de envío de textos

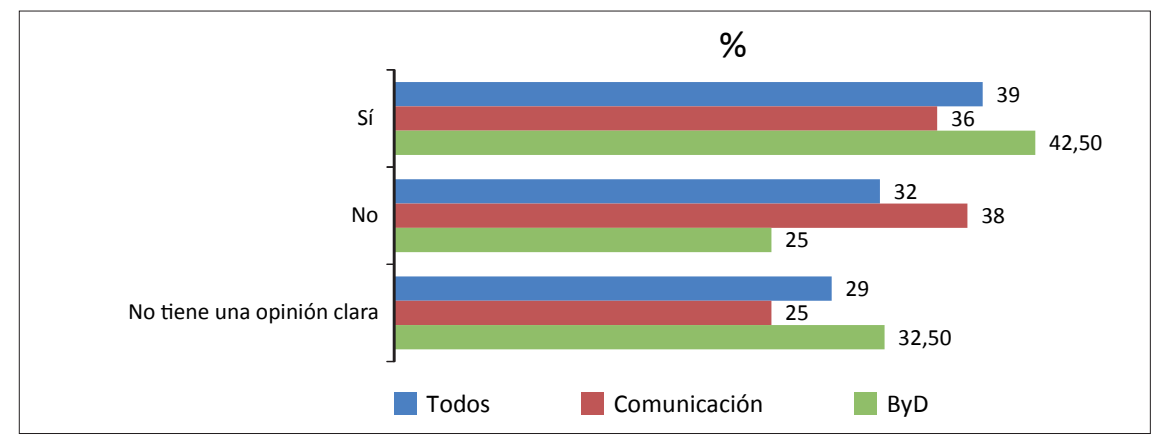

Gráfico 6. Opinión sobre la claridad de las editoriales en el proceso de revisión de textos

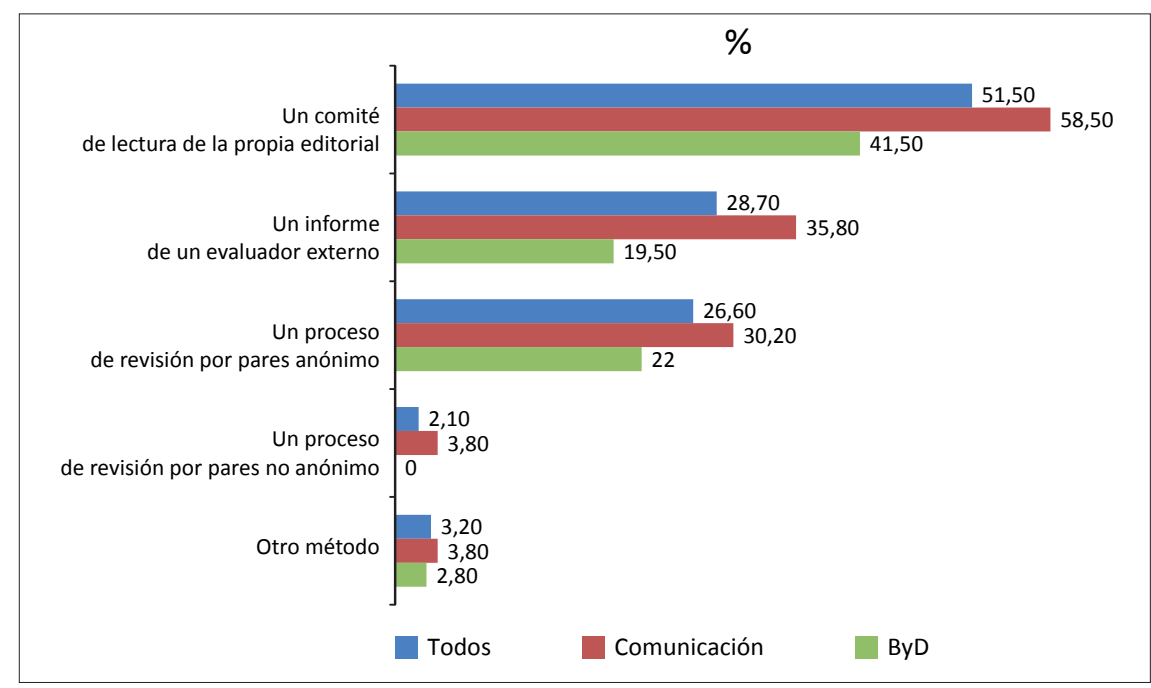

Gráfico 7. Proceso de revisión científica profesión en torno a los sistemas de evaluación, o bien con el propio comportamiento, en conjunto, de las editoriales de esa área, que las haga distintas a las del área de Biblioteconomía y Documentación.

\section{Proceso de revisión científica por parte de la editorial}

Para conocer el proceso de revisión científica que llevan a cabo las editoriales, en primer lugar se preguntaba a los investigadores si se habían sometido a estos procesos. El 38\% señaló que sí; en algunas ocasiones un 32,5\%; un 19\% que lo desconoce; y un $10 \%$ responde negativamente.

Forma del proceso de revisión científica por parte de la editorial

Con posibilidad de múltiple respuesta, el 51,5\% de los investigadores señalaron el comité de lectura de la propia editorial como el órgano encargado de la evaluación de la obra. Con porcentajes ya menores aparecen el resto de opciones: evaluación mediante un informe de un evaluador externo $(28,7 \%)$; revisión por pares anónimos (26,6\%); y revisión por pares no anónima $(2,1 \%)$. Además, dos investigadores señalaron que la revisión fue realizada por el coordinador de la colección o del libro entero (gráfico 7).

Comunicación de los motivos de un rechazo editorial

La encuesta incluyó una pregunta sobre si las editoriales habían dado razones a los autores para justificar el rechazo de un manuscrito. Contestaron 59 personas, de las cuales 32 indicaron que no procedía, es decir, que sus obras no habían sido rechazadas. 10 indicaron que siempre se les había proporcionado esa información y 9 que no la habían recibido. También cabe señalar que 3 investigadores indicaron que sí se les proporcionó la información, pero no con suficientes detalles.

\section{Pago a la editorial para la publicación}

En una pregunta directa se pedía a los investigadores que señalaran si alguna vez habían pagado a una editorial para la edición y publicación de un texto científico suyo. 6 investigadores señalaron que sí que lo habían hecho, lo que representa el $8,3 \%$ de los que contestaron a la pregunta. Las 6 respuestas procedieron del área de Comunicación (gráfico 8).

\section{Intención de pagar a la editorial para la publicación}

Complementando la pregunta anterior, se les pedía que indicaran si estarían dispuestos a pagar a una editorial para la edición de un texto científico suyo. 


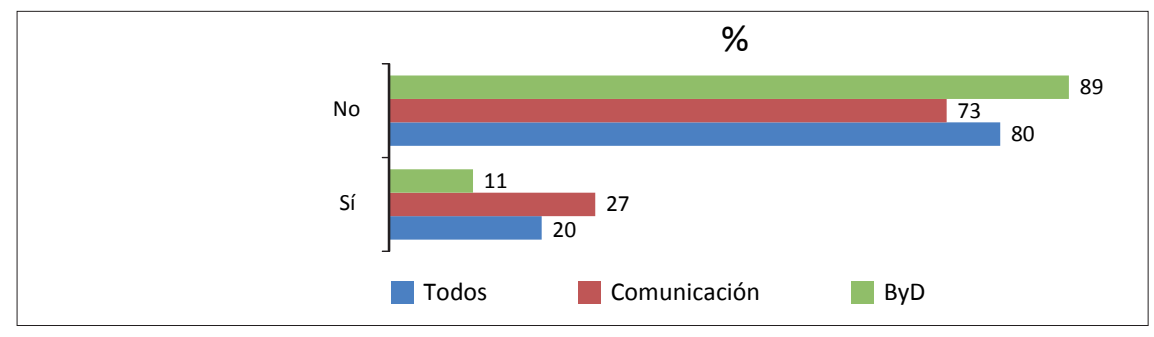

Gráfico 8. Investigadores que pagarían a una editorial para publicar

También el porcentaje mayoritario de respuesta ha sido el "no" (80\%), aunque hubo 17 casos que señalaron que sí que podrían pagar (un 20\%). Por áreas, los investigadores de Comunicación se muestran más abiertos a la idea del pago para publicar.

\section{Discusión y conclusiones}

Son muchos los aspectos que intervienen en el concepto de "calidad" de una editorial. Sin embargo, parece que son sólo unos pocos los realmente determinantes. Al poner en relación los resultados de los dos primeros apartados de este trabajo (valoración de las características de calidad de una editorial y razones para elegir una editorial para publicar) se observa bastante coincidencia en los resultados. Básicamente, se considera muy relevante la especialización temática, el prestigio y el sistema de difusión y distribución editorial. Resulta llamativo que la evaluación por expertos se considere el aspecto fundamental (y el que presenta más consenso en la comunidad científica) para conocer la calidad de una editorial $y$, sin embargo, no aparece mencionado como un criterio selectivo. Cabe imaginar que todos los investigadores presuponen que esa evaluación del original se llevará a cabo de forma rigurosa pero, en cualquier caso, destaca que no se señale como una condición para seleccionar una editorial.

Las editoriales deberían ser más transparentes en cuanto a sus procesos de selección, habida cuenta de que desempeñan su actividad en el ámbito científico

En cuanto al "prestigio editorial" que también aparece destacado, existen problemas para definirlo y objetivarlo, pero al mismo tiempo es un aspecto clave en la evaluación de la actividad científica. Es relevante conocer qué editoriales son consideradas prestigiosas por la comunidad científica, tratando así de facilitar una aproximación sobre esa difusa variable de calidad.

Atendiendo a la relación de editoriales españolas más prestigiosas que se obtiene de esta encuesta destaca que, tanto en Documentación como en Comunicación, las editoriales más "votadas" son las más especializadas de cada disciplina, las que publican más títulos sobre ambas disciplinas. Probablemente no todos los títulos de esas editoriales tengan la misma calidad o no todas hayan pasado por el mismo proceso de selección, pero la especialización hace que la editorial sea referente para el investigador. En Documentación destacan las editoriales Trea, Síntesis y Fundación Germán
Sánchez Ruipérez, mientras que en Comunicación lo hacen Paidós, Cátedra, Gedisa y Ariel.

Cabe añadir que se citan editoriales que, aunque no mantengan su actividad editorial o hayan cerrado, los investigadores reconocen como relevantes en el área por las obras editadas en el pasado (como la Fundación Germán Sánchez Ruipérez). También se citan editoriales que no son especializadas en el área (como Pirámide y $R a-M a$ ) pero que publican obras de disciplinas conexas para el área como la Informática.

Entre el resto de editoriales mencionadas predominan las de carácter multidisciplinar, aunque de vez en cuando aparece alguna más especializada como Arco libros y Eunsa para Documentación o Fragua y la Filmoteca española para Comunicación. Esta tendencia se invierte en el caso de las editoriales extranjeras ya que las que aparecen como más relevantes son reconocidas en el resto de disciplinas, grandes editoriales multidisciplinares o grandes grupos editoriales. Varían, eso sí, de una disciplina a otra. En Documentación destacan Elsevier, Springer y McGraw Hill, mientras que en Comunicación son Sage, Routledge y McGraw Hill las que aparecen mejor posicionadas.

Se detecta una mayor dispersión en las editoriales extranjeras citadas, quizá porque la oferta editorial extranjera y especializada sea mayor. Será interesante comprobar si esto es así en todas las disciplinas.

Otro de los aspectos analizados en este trabajo se refiere al tipo de editoriales elegidas para publicar. Los resultados muestran una predominante pauta de publicación: se publica más en editoriales españolas que en las extranjeras. Es decir, a partir de las personas que contestaron la encuesta, se puede afirmar que la internacionalización, medida por la publicación en editoriales extranjeras, aún no es una realidad. Sin embargo, es muy probable que este comportamiento vaya cambiando, tal y como ha sucedido con la publicación de artículos en el campo de la Comunicación (Masip, 2011; Fernández-Quijada, 2011). Sí es cierto que se detectan mayores porcentajes de publicación en editoriales extranjeras en el caso de la Comunicación que en el de la Documentación, lo que tiene que ver-probablemente-con una mayor madurez de la Comunicación como disciplina, una mayor trayectoria en investigación y una mayor masa crítica.

Aunque la participación podría haber sido más alta, los resultados son sin duda orientativos. Una próxima edición de la encuesta -prevista para 2012- permitirá ratificar o corregir los resultados. Esta primera fase del proyecto permite conocer el núcleo de editoriales reconocidas por los investigadores. En cualquier caso, si estos resultados se emplearan de forma orientativa -sólo podría hacerse así- en algún proceso de evaluación, sería necesario acompañarlos de la opinión de algunos expertos del área que pudiera valorar aquellas editoriales que no hayan aparecido en el estudio y que puedan resultar relevantes.

Respecto a la forma de contacto entre autor y editor para iniciar el proceso de publicación de una obra, se identifica una 
práctica predominante distinta en cada caso. En Documentación es más frecuente que la editorial contacte con el autor, y ello puede tener que ver con la menor trayectoria de las editoriales especializadas en el área. La Documentación como disciplina universitaria y de investigación es joven y eso tiene su reflejo en un menor número de editoriales especializadas. Puede explicarse, por tanto, que en estos primeros años de andadura, las editoriales hayan tenido que buscar a sus autores. Nuevamente, y como señal de una mayor madurez, los hábitos en Comunicación son diferentes y el mayor porcentaje de respuestas (64\%) corresponde a la fórmula en la que la editorial se pone en contacto con el autor.

Predominan las críticas de los investigadores hacia la falta de información y transparencia de las editoriales sobre política editorial, selección y envío de manuscritos, etc.

Una de las conclusiones más destacadas de este trabajo se refiere a la percepción que tienen los autores de las editoriales: predominan las críticas hacia la falta de información y transparencia sobre la política editorial, la selección y envío de manuscritos, etc. Esto, sin duda, debe ser conocido por las editoriales que, actualmente, lo quieran o no, desempeñan su labor en un entorno muy competitivo (el académico) y deben adecuarse a las mismas exigencias de calidad que se dan en las revistas científicas. Al fin y al cabo, el núcleo de su actividad es la investigación llevada a cabo y escrita por los investigadores. Sin las obras no hay editoriales. Y parece que la comunidad científica demanda más claridad y rigor en los procedimientos.

Los porcentajes de "desconocimiento" de las prácticas editoriales son abultados y señal inequívoca de que las editoriales deberían ser más transparentes en cuanto a sus procesos de selección, habida cuenta de que desempeñan su actividad en el ámbito científico, en el que la evaluación por expertos debe ser un aspecto clave. De hecho, tal y como apuntan los resultados de este estudio, la evaluación por expertos es un elemento determinante de la calidad de una editorial. El hecho de que las editoriales adopten una política de transparencia en este asunto no anularía su autonomía como empresas, sino más bien ayudaría a mejorar su marca, más vinculada en ese caso a calidad editorial.

Los porcentajes registrados en la pregunta sobre procesos de revisión científica a los que se han sometido los investigadores no son buena señal de lo extendidos (o poco extendidos) que están los procesos de revisión. Sin duda, convendría que las editoriales no sólo ofrecieran información más clara y completa sobre los procesos de evaluación sino, sobre todo, que los aplicaran y fuera evidente para autores y para lectores.

Otra de las conclusiones es que la revisión externa de los originales no es la más extendida, sino que es más habitual la realizada por los comités de lectura de la propia editorial. Nuevamente surge aquí la inevitable comparación con las revistas científicas, a las que se exige, cada vez más, que la evaluación sea externa a la entidad editora y a los consejos de redacción. Sería necesario reflexionar sobre la autonomía de los procedimientos de selección en editoriales -mayoritariamente privadas- frente a los cada vez más reglamentados procedimientos de selección en revistas científicas - mayoritariamente editadas por instituciones públicas-. Dicho de otro modo, cabe plantearse si deben prevalecer las condiciones de la publicación científica (revisada por expertos) o si deben hacerse distinciones en función de los objetivos de las editoriales.

Por otra parte, aunque las respuestas sobre la práctica del pago por publicar son muy limitadas y de ellas se deduciría que no es habitual, lo cierto es que entre los comentarios surge de forma recurrente la idea de que muchos investigadores pagan por publicar precisamente por la presión que existe sobre ellos de contar con publicaciones. También se alude a que en la solicitud de proyectos ya se puede contemplar alguna partida para publicar pero ciertamente esto abre un debate sobre la financiación de la investigación y la publicación, sobre los intereses que se crean y sobre la posible preponderancia del dinero sobre el criterio de excelencia científica.

La comunidad científica de humanistas $y$, en menor medida, científicos sociales viene reclamando desde hace tiempo la consideración o mejor valoración de las monografías en los procesos de evaluación de la actividad científica. Los comentarios vertidos en esta encuesta son una muestra más de ello-además de reflejar la creciente presión por publicar-, y los resultados de este estudio representan un primer paso en la concreción de esas valoraciones.

La revisión externa de los originales no es la más extendida, sino que es más habitual la realizada por los comités de lectura de la propia editorial

\section{Notas}

1. Agència per a la Qualitat del Sistema Universitari de Catalunya (AQU Catalunya).

http://www.aqu.cat

2. Categorización de publicaciones científicas en Ciencias Humanas y Sociales. 2004410E607. Financiado por el CSIC.

3. La mayor desviación típica $(1,3)$ se ha dado en la opción de respuesta sobre el formato electrónico.

\section{Agradecimientos}

Los autores agradecen su participación a los investigadores y profesores que respondieron la encuesta, así como el trabajo técnico de Sonia Jiménez, y de la Unidad de Análisis Estadístico y de la Unidad TIC del Centro de Ciencias Humanas y Sociales (CCHS) del CSIC.

\section{Bibliografía}

Aneca. Programa Academia. Principios y orientaciones para la aplicación de los criterios de evaluación. Madrid: Aneca, 2008. 
http://www.aneca.es/var/media/557171/academia ppiosyorientaciones_100616.pdf

Anep. Criterios de calidad en la investigación en humanidades. Madrid: Anep/Fecyt, 2007.

AQU Catalunya. L'avaluació de la recerca en humanitats $i$ ciències socials. Barcelona: AQU Catalunya, 2010.

http://www.aqu.cat/publicacions/quaderns_qualitat/ qqhum_ccsoc.html

BOE. Resolución de 18 nov. 2009, de la Presidencia de la Comisión Nacional Evaluadora de la Actividad Investigadora, por la que se establecen los criterios específicos en cada uno de los campos de evaluación, 2009, pp. 102491-102505.

http://www.boe.es/boe/dias/2009/12/01/pdfs/BOE-A2009-19218.pdf

Cullars, John M. "Citation characteristics of monographs in the fine arts". Library quarterly, 1992, v. 62, n. 3, pp. 325-342.

Cullars, John M. "Citation characteristics of English-language monographs in philosophy". Library \& information science research, 1998, v. 20, n. 1, pp. 41-68.

Fernández-Quijada, David. "De los investigadores a las redes: una aproximación tipológica a la autoría en las revistas españolas de comunicación". En: Simposio AEIC 2011. Investigar la comunicación en España: proyectos, metodologías y difusión de resultados.

http://eprints.rclis.org/handle/10760/15566

Giménez-Toledo, Elea; Román-Román, Adelaida. “As- sessment of humanities and social sciences monographs through their publishers: a review and a study towards a model of evaluation". Research evaluation, 2009, v. 18, n. 3, pp. 201-213.

http://dx.doi.org/10.3152/095820209X471986

Glänzel, Wolfang; Schoepflin, Urs. "A bibliometric study of reference literature in the sciences and the social sciences". Information processing and management, 1999, v. 35, pp. 31-44.

Hemlin, Sven; Gustafsson, M. "Research production in the arts and humanities: a questionnaire study of factors influencing research performance". Scientometrics, 1996, v. 37, n. 3, 417-432.

Masip, Pere. "Los efectos del efecto Aneca: análisis de la producción española en Comunicación en el Social Science Citation Index (1999-2009)". En: Simposio AEIC 2011. Investigar la comunicación en España: proyectos, metodologías y difusión de resultados.

http://www.revistacomunicar.com/pdf/2011-04-Masip.pdf

Masip, Pere. "Efecto Aneca: producción española en comunicación en el Social science citation index". Anuario ThinkEPI, 2011, v. 5, pp. 206-210.

Moed, Henk F.; Luwel, Marc; Nederhof, Anton J. "Towards research performance in the humanities". Library trends, 2001, v. 50, n. 3, pp. 498-520.

http://findarticles.com/p/articles/mi_m1387/is_3_50/ai_ 88582627

\section{ESTUDIOS DE CIENCIAS DE LA INFORMACIÓN YDE LA DOCUMENTACIÓN}

\section{¿QUÉ MEJOR QUE}

DOMINAR LOS PROCESOS

DE LA INFORMACIÓN

\section{EN LA SOCIEDAD DE LA INFORMACIÓN?}

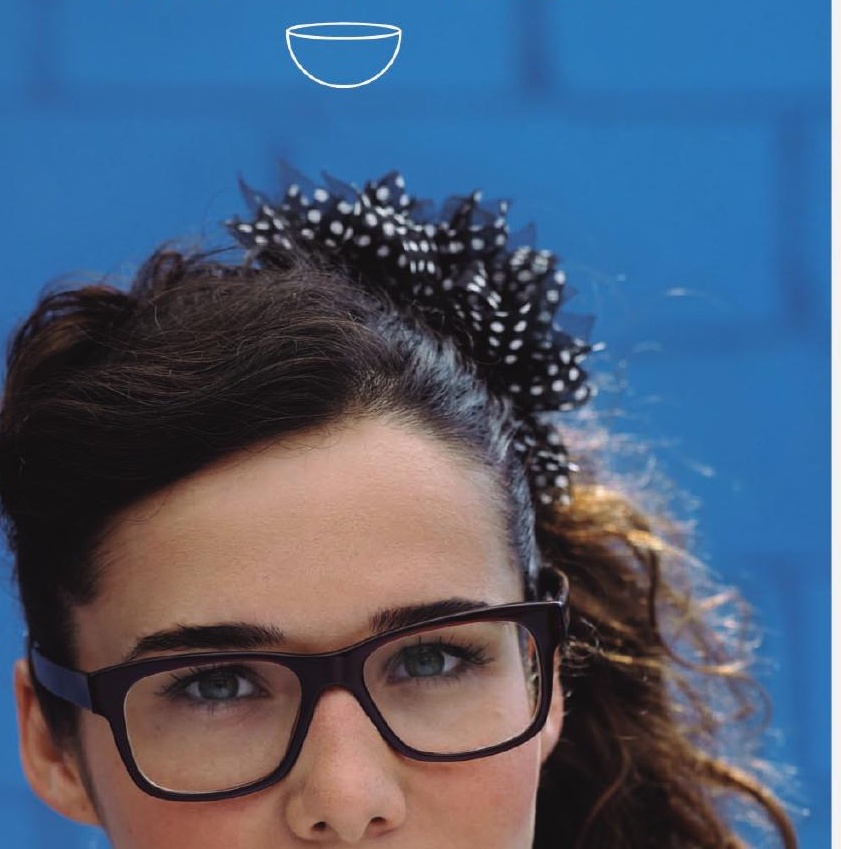

\section{GRADOS}

INFORMACIÓNY DOCUMENTACIÓN

COMUNICACIÓN

\section{POSGRADOS}

GESTIÓN DE LA INFORMACIÓNY EL CONOCIMIENTO

ANÁLISIS Y MEDICIÓN DE LA INFORMACIÓN UOC-ACCESO

ARQUITECTURA DE LA INFORMACIÓNY REDES SOCIALES

EL PROFESIONAL DE LA INFORMACIÓN DE SALUD EN LA SOCIEDAD

2.O UOC-ANIS

PERIODISMO MULTIMEDIA UOC-ACN

PERIODISMO DIGITAL UOC-EL PERIÓDICO-LAVINIA

INNOVACIÓN EN CREACIÓN DE CONTENIDOS AUDIOVISUALES

UOC-DIGITALENT

COMUNICACIÓN CORPORATIVAE INSTITUCIONAL

ENTRETENIMIENTO UOC-TV3

PUBLICIDAD EN INTERNET UOC-DOUBLE YOU

APRENDIZAJEY TRABAJO COLABORATIVO EN RED

Acceso Abierto

$\mathbf{7}$

...............................

Consulta todos los programas de los Estudios de Ciencias de la Informacióny Comunicación en www.uoc.edu

MENTES ABIERTAS

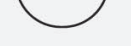

